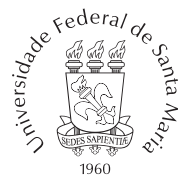

DOI: http://dx.doi.org/10.5902/2236672536812

Recebido em: 08/02/2019. Aprovado em: 16/08/2019.

\title{
NEGOCIANDO DIFERENÇAS CULTURAIS E DE GÊNERO ESSENCIALIZADAS EM UM MUNDO GLOBAL: BRASILEIROS EM LONDRES ${ }^{a b}$.
}

\author{
NEGOTIATING ESSENTIALISED CULTURAL AND \\ GENDERED DIFFERENCES IN A GLOBAL WORLD: \\ BRAZILIANS IN LONDON. \\ LA NÉGOCIATION DES DIFFÉRENCES CULTURELLES ET DE \\ GENRE ESSENTIALISÉS DANS UN MONDE GLOBALISÉ: \\ LES BRÉSILIENS À LONDRES. \\ NEGOCIANDO DIFERENCIAS CULTURALES Y DE \\ GENERO ESENCIALIZADAS EN UN MUNDO GLOBAL: \\ BRASILEÑOS EN LONDRES. \\ Angelo Martins Jr.* \\ iD https://orcid.org/0000-0002-0878-8096
}

\begin{abstract}
RESUMO: Nas últimas décadas, estudiosos transnacionais têm analisado o papel dos laços sociais na produção de conexões que ligam pessoas em diferentes lugares do mundo, dentro de um contexto de intensa mobilidade e de bens na chamada "era móvel". Em discussões sobre etnia, nacionalidade e a formação de "comunidade étnica" no exterior, os estudos transnacionais, no entanto, celebram com demasiada facilidade a "semelhança étnica" que constitui laços de afinidade baseados na experiência cultural compartilhada. No entanto, há uma falta de compreensão da experiência migratória transnacionalista em relação aos legados coloniais e às múltiplas distinções existentes entre os migrantes. Neste artigo, contribuo para a discussão sobre a experiência transnacional, demonstrando como os brasileiros em Londres estão constantemente ressignificando e negociando representações essencializadas e estigmatizadas de dife-

\footnotetext{
${ }^{a}$ Pesquisa financiada pela Coordenação de Aperfeiçoamento de Pessoal de Nível Superior (CAPES), programa doutorado pleno.

${ }_{b}^{b}$ Traduzido do original, em inglês, 'Negotiating essentialised cultural and gendered differences in a global world: Brazilians in London', publicado no mesmo número deste Dossiê.

* Doutor em Sociologia pela Goldsmiths College - University of London. Pesquisador da School of Sociology Politics and International Studies, University of Bristol, Bristol, UK; E-mail: angelo. martinsjunior@bristol.ac.uk
} 
Negociando diferenças culturais e de gênero essencializadas em um mundo global: Brasileiros em Londres.

renças culturais, raciais e de gênero ao falar e interagir umas com as outras, bem como com europeus/britânicos. Os dados são resultado de uma abordagem metodológica mista, que combina etnografia em locais de lazer frequentados por brasileiros em Londres, ao longo de 18 meses (de julho de 2013 a janeiro de 2015), além de 33 entrevistas em profundidade com brasileiros em Londres.

Palavras chave: diferença; estudos transnacionais; racialização; cultura e gênero; migração brasileira.

ABSTRACT: In the last decades, transnational scholars have analysed the role of social ties in producing connections linking people in different places of the world within a context of intense mobility of people and goods in the so-called 'mobile era'. In discussions of ethnicity, nationality and the formation of 'ethnic community' abroad, transnational studies, nevertheless, often far too easily celebrate the 'ethnic commonality' constituting ties of affinity based on shared cultural experience. Yet, there is a lack of understanding of the transnationalist migratory experience in relation to colonial legacies and to the multiple distinctions existing among and between migrants. In this article I contribute to the discussion on transnational experience by demonstrating how Brazilians in London are constantly re-signifying and negotiating essentialised and stigmatised representations of cultural differences, intersected with gender and 'race', when speaking about and interacting with each other as well to western European/British people. The findings are result of a mixed methods approach, which combines ethnography in places of leisure frequented by Brazilians in London, generated over 18 months (from July 2013 to January 2015), as well as 33 in-depth interviews with Brazilians in London.

Keywords: difference; transnational studies; culture and gender; Brazilian migration.

RÉSUMÉ: Au cours des dernières décennies, plusieurs spécialistes du transnationalisme ont analysé le rôle des liens sociaux dans la production de liens entre des personnes de différentes régions du monde, dans un contexte de forte mobilité des personnes et des biens à l'ère dite "mobile". Dans les discussions sur l'ethnicité, la nationalité et la formation d'une "communauté ethnique" à l'étranger, les études sur le transnationalisme célèbrent cependant trop facilement la "similitude ethnique" qui constitue des liens d'affinité basés sur une expérience culturelle partagée. Cependant, il existe un manque de compréhension de l'expérience de la migration transnationale en ce qui concerne l'héritage colonial et les 
multiples distinctions entre et parmi les migrants. Dans cet article, je contribue à la discussion sur l'expérience transnationale en démontrant que les Brésiliens à Londres redéfinissent et négocient en permanence des représentations essentialisées et racialisées des différences culturelles, raciales et entre les hommes et les femmes en parlant et en dialoguant, ainsi qu'en Europe et en Angleterre. Les données sont le résultat d'une approche mixte combinant ethnographie sur des sites de loisirs fréquentés par des Brésiliens à Londres sur une période de 18 mois (juillet 2013 à janvier 2015), ainsi que 33 entretiens approfondis avec des Brésiliens à Londres.

Mots-clés: différence; études transnationales; racialisation; culture et genre; migration brésilienne.

RESUMEN: En las últimas décadas, los académicos transnacionales han analizado el papel de los lazos sociales en la creación de conexiones que conectan personas en diferentes lugares del mundo en un contexto de movilidad intensa de personas y mercaderías en la llamada "era móvil". En las discusiones sobre etnicidad, nacionalidad y la formación de una "comunidad étnica" en el extranjero, los estudios transnacionales, sin embargo, a menudo celebran con demasiada facilidad los "elementos étnicos" que constituyen vínculos de afinidad basados en experiencias culturales compartidas. No obstante, hay una falta de comprensión de la experiencia migratoria transnacionalista en relación con los legados coloniales y las múltiples distinciones existentes entre los migrantes. En este artículo, contribuyo a la discusión sobre la experiencia transnacional demostrando cómo los brasileños en Londres están constantemente volviendo a significar y negociando las representaciones esencializadas y racializadas de las diferencias culturales, "raciales" y de género cuando hablan e interactúan entre sí y con europeos/británicos. Los hallazgos son el resultado de un enfoque de métodos mixtos, que combina la etnografía en lugares de entretenimiento frecuentados por brasileños en Londres, generados durante 18 meses (desde julio de 2013 hasta enero de 2015), así como 33 entrevistas en profundidad con brasileños en Londres.

Palabras clave: diferencia; estudios transnacionales; racialización; cultura y género; migración brasileña. 


\section{INTRODUÇÃO}

Neste artigo procuro analisar como brasileiros em Londres estão constantemente ressignificando e negociando representações essencializadas e muitas vezes estigmatizadas de diferenças culturais, interseccionadas com gênero e "raça", ao falar e interagir uns com os outros, bem como com europeus ocidentais/britânicos. Isso é feito dentro do conturbado ambiente político do Reino Unido, no qual imagens midiáticas e políticas do 'migrante' são construídas através de narrativas racistas e discriminatórias que representam 'migrantes' como corpos incivilizados que ameaçam a 'cultura britânica' (Tyler, 2013; Anderson, 2013).

Nas últimas décadas, estudiosos transnacionais (Vertovec, 1999; Levitt 2001; Levitt e Jaworsky, 2007) analisaram o papel dos laços sociais na produção de conexões transnacionais ligando pessoas em diferentes lugares do mundo dentro de um contexto de intensa mobilidade de pessoas e mercadorias na chamada "era móvel” (Urry, 2008). Essa análise foi para além da compreensão da migração apenas como resultado das disparidades econômicas globais, considerando, por exemplo, como a presença de migrantes em determinados locais de destino influenciam, facilitam ou até predizem a chegada de novos migrantes (Tilly, 1990; Massey, 1990, Levitt 2001). Em discussões sobre etnia, nacionalidade e a formação de "comunidades étnicas" no exterior (Light e Gold, 2000), estudos transnacionais, entretanto, celebram com demasiada facilidade a "semelhança étnica/nacional" que constitui laços de afinidade. Etnia e/ou nacionalidade, nesses estudos, resultaria em um sentimento de camaradagem transnacional forjada em experiências culturais compartilhadas anteriormente, que também tem sido chamada de "solidariedade étnica" (Light and Gold, 2000; Portes, 1995). Assim, "um sentimento de pertença a uma" cultura "comum" (Djelic e Quack, 2010, p.xix) resultaria na formação de comunidades transnacionais compostas por "migrantes que se ajudam emocionalmente, que empreendem todos os tipos de atividades de lazer em conjunto, que compartilham informações sobre vários aspectos da vida na sociedade receptora, e que ajudam uns aos outros a encontrar emprego" (Roggeveen e Van Meeteren, 2013, p.1079). 
Desse modo, estudiosos transnacionais tendem, então, a considerar a comunidade e a solidariedade étnica/nacional entre os migrantes do mesmo grupo nacional como um dado e não como um objeto de pesquisa, como bem demonstra Martes e Fazito (2010). Este é frequentemente o caso na maioria da literatura sobre brasileiros no exterior no final da década de 1990 e 2000 (Soares, 2002; Goza, 2003; Assis et al, 2010). No entanto, alguns estudiosos também identificaram como os brasileiros costumam problematizar sua relação com a chamada "cultura brasileira". Pesquisas com brasileiros em Boston (Martes, 2011) e em Los Angeles (Beserra, 2000), por exemplo, mostraram que, embora brasileiros tivessem uma atitude geralmente positiva em relação à "cultura americana", o mesmo não se estendia com a mesma intensidade à 'cultura brasileira'. Estudos com brasileiros nos EUA também demostraram, de maneira importante, como a identificação étnica/nacional tem uma natureza instrumental entre o referido grupo. Narrativas de uma "cultura brasileira" valorizada surgem quando tentam construir uma identidade em oposição aos hispânicos através de um discurso de não ser "como os hispânicos", visto como o "outro inferior" e representado como mais pobres e menos instruídos do que os brasileiros (Margolis, 2003; Martes, 2003). Por outro lado, não importa o quanto a categoria hispânica seja indesejável, isso não significa que os brasileiros não adotem essa identificação em circunstâncias específicas e de forma instrumental: quando podem se beneficiar de um sistema de cotas, por exemplo (ver Oliveira, 2003). Assim, processos contínuos de diferenciação e "desidentificação" cultural são centrais nas formas pelas quais migrantes brasileiros constroem e negociam suas vidas no exterior.

No entanto, os estudos mencionados acima muitas vezes não consideram, por exemplo, como a 'cultura brasileira', que os brasileiros evitam se identificar, é carregada de estigmas que estão historicamente vinculados às representações racistas e discriminatórias dos corpos e da cultura brasileira como 'inferiores' e incivilizados. De modo geral, apesar dos importantes insights fornecidos pelo transnacionalismo, o que é notavelmente ausente em tais discussões é a consideração de como o presente 'global (móvel)' ainda produz hierarquias 'raciais' e étnicas construídas em conexão com os lega- 
dos globais do passado colonial (Gilroy, 1993). Bhambra, 2013). Dialogando com Grosfoguel et al (2014), argumento que há uma falta de compreensão da experiência migratória transnacionalista em relação aos legados coloniais e às múltiplas distinções existentes entre os migrantes. Assim, juntando-se a um grupo de estudiosos brasileiros da migração que examinaram empiricamente experiências migratórias em relação aos legados coloniais (ver Beserra, 2000; Gomes, 2013; Malheiros e Padilla, 2014; Togni, 2014), neste artigo avanço a discussão sobre transnacionalismo, questionando como migrantes negociam e refazem hierarquias nacionais, 'raciais' e étnicas, historicamente enraizadas, num mundo cada vez mais conectado, mas ainda dividido (Back e Sinha, 2018). Mais especificamente, como brasileiros negociam as representações estigmatizadas da "cultura brasileira", como exótica e incivilizada, em comparação com a “cultura da Europa Ocidental". É importante notar que, embora uma análise abrangente e detalhada do funcionamento de 'raça' e gênero esteja fora do escopo deste artigo, levarei em conta como gênero e 'raça' frequentemente importam quando os brasileiros falam deles próprios e outros grupos, em Londres, em termos "culturalistas".

Com base em entrevistas e notas etnográficas, organizo o artigo em três seções. Inicialmente, estruturo teoricamente a produção e a negociação da diferença e da cultura que molda este artigo. Em seguida, analiso como os brasileiros tendem a se inferiorizar em comparação aos europeus ocidentais/britânicos, por meio da reconstrução, em um novo contexto, de relatos essencializados da cultura, interseccionada com 'raça' e gênero, os quais são historicamente produzidos desde a colonização. Depois, analiso como os brasileiros constantemente negociam representações essencializadas da "cultura brasileira", entrecruzadas com representações de gênero, reformulando tanto a "cultura britânica" quanto a "brasileira" em contextos específicos - como naqueles em que eles têm que lidar com discriminação direta ou em quando "ser brasileiro" adquire um valor simbólico positivo.

Aqui, faço dialogar os achados empíricos de minha pesquisa com as teorias pós-coloniais e de-coloniais (Gilroy, 1993; Bhambra, 2013; Grosfoguel, 2011; Grosfoguel et al, 2014), bem como com teorias das representações sociais enquanto categorias sociais dinâmi- 
cas que são continuamente produzidas e negociadas nas disputas das classificações sociais (Hall, 1997; Sayad, 2004), defendo que, para compreendermos as experiências cotidianas dos migrantes transnacionais é necessário entender como as categorias da diferença no presente (neste caso particular, diferença cultural, de gênero e racial) continuam a produzir reestruturadas relações hierárquicas, construídas na era colonial e pós-colonial.

Empiricamente, este artigo é resultado de um projeto de pesquisa que adotou uma abordagem metodológica mista, produzindo 180 páginas de notas etnográficas, geradas ao longo de 18 meses (de julho de 2013 a janeiro de 2015), além de 33 entrevistas em profundidade com brasileiros. Londres. Os migrantes brasileiros, em geral, tendem a ser um grupo diverso, composto por pessoas de diferentes classes sociais, regiões, gêneros e motivadas por diferentes ambições. Apesar de sua diversidade, a população brasileira no exterior não é composta das pessoas mais pobres ou menos instruídas do país (Martes, 2011; Oliveira, 2014; Evans et al, 2011). Estudos quantitativos sobre brasileiros em Londres tendem a retratar descobertas similares (McIlwaine et al, 2011; Evans et al, 2011). Brasileiros em Londres são uma população jovem, com alto nível educacional (em relação à população brasileira como um todo) ${ }^{1}$ e proveniente de diversas regiões. No entanto, os estados das regiões Sul e Sudeste contribuem com a maior proporção de migrantes, com os maiores números vindos de São Paulo, Minas Gerais, Paraná, Rio Grande do Sul e Rio de Janeiro, seguidos por Goiás, da região central do país (Evans et al, 2011).

Como minha pesquisa focou nas interações entre diferentes grupos de brasileiros em Londres, foi necessário trabalhar com participantes de diferentes origens e com diversas razões para estar em Londres. Assim, eu indutivamente selecionei três grupos diferentes de pessoas: aqueles que estão em Londres realizando os chamados "trabalhos não qualificados" no setor de serviços, como faxineiros e garçons; aqueles que tinham anteriormente realizado "trabalhos não qualificados", mas tinham experienciado a mobilidade ocupacional em Londres; e aqueles

$1 \mathrm{O}$ número médio de anos de estudo entre os brasileiros com mais de 15 anos vem aumentando nas últimas décadas, mas permanece muito baixo. Aumentou de 4 anos de estudo em 1980 para $6,2 \mathrm{em} 2000$ (IBGE / SIDRA, 2000). A maioria dos brasileiros, em Londres, tem pelo menos as qualificações do ensino médio ou diplomas universitários (Evans et al, 2011). 
que vieram para o Reino Unido já realizando atividades que não são vistas como "empregos de migrantes" (desqualificados), como estudantes de pós-graduação e profissionais liberais (funcionários de universidade, empresários, advogados e médicos). Utilizei o trabalho como um meio de dividir esses grupos devido ao fato de que ocupação é um marcador importante quando brasileiros falam sobre as divisões existentes dentro da população. Entrevistei 11 pessoas de cada grupo: 17 homens e 16 mulheres, entre 21 e 54 anos (ver Martins Jr e Knowles, 2017 para uma detalhada discussão metodológica do projeto).

\section{ENQUADRANDO A DIFERENÇA E A CULTURA NUM "MUNDO EM MOVIMENTO"}

Com base em dados obtidos no decorrer da pesquisa, defendo que para entender a produção e a negociação da diferença em um "mundo em movimento", precisamos enquadrar a "diferença" nem sempre como um marcador de hierarquia e opressão, mas como algo contextualmente contingente. Em outras palavras, precisamos analisar o conceito "diferença" através da "variedade de maneiras pelas quais discursos específicos de diferença são constituídos, contestados, reproduzidos ou ressignificados" (Brah, 1996, p.225). Neste artigo, presto atenção às circunstâncias que permitem que a "diferença" seja organizada hierarquicamente. Ao fazer isso, olho para os momentos nos quais a "diferença" se torna a modalidade pela qual a dominação se articula, resultando, assim, na produção e na negociação de hierarquias. No entanto, tomando emprestado de Brah (1996), a fim de compreender tais processos, precisamos de uma estrutura conceitual que não privilegie nem o nível macro ou micro de análise, nem um eixo específico de diferenciação, como classe ou 'raça'. Em vez disso, precisamos teoricamente explicar como a articulação de discursos e práticas, historicamente incorporados, moldam relações sociais, posições de sujeito e subjetividades através de múltiplos eixos de diferenciação. Neste artigo, vemos tal articulação acontecendo através dos marcadores de cultura, raça' e gênero.

Além disso, marquei a "cultura" brasileira (e da Europa Ocidental) com aspas quando a cultura é tomada como uma caracte- 
rística essencializada que determina de forma homogênea o comportamento daqueles que a compartilham. Seguindo Brah (1996), eu considero a "cultura nacional" como um processo diverso e dinâmico que está em construção permanente. E o Brasil, por exemplo, é um país grande e diversificado, com grandes diferenças regionais. Ao fazer minhas entrevistas, encontrei diferentes versões de "Brasil" e de "sua cultura", construídas em diferentes narrativas regionais e de classec. No entanto, quando analiso "a cultura brasileira", neste artigo, estou analisando uma representação essencializada, que também possui características raciais e de gênero, muitas vezes presentes nas imaginações europeias e brasileiras. Por exemplo, presume-se, frequentemente, que o Brasil tenha uma cultura exótica e hibrida, que não o permite que se torne um país civilizado moderno. Eu traço a construção histórica desta representação, neste artigo, através das narrativas dos meus entrevistados.

Não estou sugerindo, no entanto, que não existam diferenças culturais entre brasileiros e europeus. A cultura é essencialmente um processo, mas isso não significa que não possamos falar sobre especificidades e artefatos culturais - como costumes, tradições e valores (Brah 1996, p.231). A cultura, como observa Omar Lizardo (2010, p.19), dialogando com Bourdieu (1996), é também um sistema de ação e percepção que é adquirido em um estado tácito ao longo da trajetória do indivíduo. Ela compõe todos os processos que são inscritos nos corpos, "que é ao mesmo tempo escondido e exibido, em gestos, posturas, maneiras de transportar (portar) o corpo e se comportar com o corpo" (Sayad, 2004, p.261). No entanto, tais especificidades culturais não constituem necessariamente divisões sociais. Nem as diferenças culturais são apenas o resultado de um processo simples de diferenciação. De fato, a diferença cultural pode ser a base de imperativos discriminatórios quando tal "diferença" é construída dentro dos interstícios das relações sócio-políticas e econômicas, nas quais os grupos sociais (e suas “culturas") - com acesso diferenciado à riqueza, ao poder e ao privilégio - são classificados em relação uns ao outros"(Brah, 1996, p.19) - como é o caso dos brasileiros e dos europeus ocidentais. 
Negociando diferenças culturais e de gênero essencializadas em um mundo global: Brasileiros em Londres.

\section{A CULTURA BRASILEIRA INCIVILIZADA E O (ENCAN- TADOR) CIVILIZADO EUROPEU / BRITÂNICO}

Nesta seção demonstro como os brasileiros em Londres tendem a reproduzir e ressignificar em novas situações e contextos, representações estigmatizadas que os inferiorizam em comparação aos europeus. Nas minhas interações com brasileiros em Londres, descobri que eles frequentemente falam em termos 'culturalistas', nos quais 'cultura', intersectada com gênero e 'raça', é conceituada como um fator independente que determina o destino daqueles que a 'possuem'. Nessas falas, brasileiros se representam a si mesmo como sendo 'corpo' (emoção/tradição) em comparação com a 'mente' europeia (razão/civilizada). Como demonstrado ao longo deste artigo, tais comparações se cruzam com "raça", pois o "ser britânico" é enquadrado pelos brasileiros como "branquidade" (valorizada). Além disso, os brasileiros tendem a tomar olhos azuis ou verdes, assim como cabelos loiros, como características muito importantes de beleza e limpeza, ligadas a traços de branquidade. A valorização de traços de "brancura" é comum onde hierarquias de cor operam em populações altamente multirraciais, como o Brasil, através de "colorismo" ou "shadismo" (como a gama de tons de pele) (Ali, 2005)2. Assim, as imagens de 'brasileiros' e 'europeus ocidentais' são construídas, nas narrativas dos participantes de minha pesquisa, com base em um conjunto de oposições homólogas embutidas em representações constituídas como parte da 'matriz colonial de poder' (Quijano , 2000). Essa matriz de poder vem, desde o colonialismo, racializando e estigmatizando corpos e espaços através da divisão hierárquica entre europeus racionais/civilizados (mente) e não-europeus emocionais/tradicionais (corpo) (Quijano, 2000). Estudos pós-coloniais afirmam que a hierarquia racial e étnica do binário europeu/não-europeu construído durante a colonização tem sido con-

2 Tais representações, tanto de brasileiros quanto de europeus, também são representações de classe. Como discuto em outro lugar (Martins Jr, 2017), a classe média brasileira usa a mesma divisão entre "corpo" e "mente" para se distinguir do "imigrante pobre". Eles são "mente" (razão) e o "migrante pobre/econômico" é "corpo" - embora neste artigo eles homogeneízem todos os brasileiros como "corpo". Ao mesmo tempo, a representação que eles têm da cultura europeia homogeneíza os europeus como "mente", ignorando a presença de pobres na Europa, que há muito tempo tem sido historicamente associada ao material e à corporificação (ver Bourdieu, 1984; Porter, 2003). 
tinuamente ressignificada desde então, justificando as desigualdades globais através da racialização de corpos e espaços como física, intelectual e moralmente inferiores, com estilos de vida não-civilizados (Grosfoguel, 2013; Said, 1979; Gilroy, 1993). Esse processo imputou características supostamente fundamentais às pessoas, "escrevendo essas qualidades de caráter em seus corpos, em seus genes e em sua natureza essencial" (Spickard, 2013, p.14), com base em sua participação em "grupos raciais" e étnicos.

Historicamente, justificativas para estigmatizar corpos e espaços não-europeus passaram de explicações baseadas em 'religião' (não possuem alma) para 'raça' (não possuem a 'biologia correta') e, contemporaneamente, para 'etnia' (não possuem a 'cultura certa') (Grosfoguel, 2013, p.83-84). Este último, "etnicidade”, impõe noções estereotipadas de "cultura comum", definindo a experiência de grupos estigmatizados principalmente em termos "culturalistas" (Brah, 1996). Como Brah (1996) argumenta, essa discriminação cultural "combina a rejeição da superioridade ou inferioridade biológica com um foco em "um modo de vida ", tendo a diferença cultural como a base "natural" para sentimentos de antagonismo em relação a estranhos" (p. 163), os quais são construídos através de uma variedade de marcadores, como gênero, religião, idioma, casta ou classe. Nesse quadro, os participantes da pesquisa usaram as seguintes palavras para descrever a divisão entre brasileiros e europeus ocidentais: grosseiro / educado, emocional / racional, incivilizado / civilizado, tradição / moderno, exótico / belo, machista (sexista) / príncipe, promíscuo / moral, corrupto / puro, ignorante / culto, desorganizado / organizado, fofoca (controle) / individualidade (liberdade), desigualdade / igualdade. Essas representações opostas geram uma repulsa e aversão à "cultura brasileira", ao mesmo tempo que resulta em um encantamento e desejo pelo que definem como "cultura britânica", conforme discutido abaixo.

\section{1 "Culturalizando" razões para viver no exterior}

Ao analisar suas vidas em Londres, brasileiros frequentemente fazem comparações entre a cultura brasileira e a europeia ocidental/britânica como uma das razões para deixar o Brasil, bem 
como para não retornar ao país. A representação da cultura europeia/britânica tende a adquirir um valor positivo e ser contraposta à cultura brasileira por meio de um conjunto de oposições homólogas que estavam presentes nas mentes brasileiras antes mesmo de migrarem. Parece haver um encanto tácito com a cultura da Europa Ocidental, que é considerada "a cultura", a referência universal a ser seguida. Assim, é comum ouvir pessoas citando a cultura brasileira, supostamente inferior / imoral, e a sua falta de "civilidade" para explicar o desejo de tentar viver em Londres e, uma vez lá, não querem retornar ao Brasil, como em minha conversa com Rachel, brasileira de 42 anos que vive em Londres há 12 anos.

É difícil viver no Brasil. Há muita fofoca, pessoas querendo saber tudo sobre sua vida pessoal, tentando controlar tudo, com quem você está saindo, como se veste, quando elas mesmas não sabem como se vestir adequadamente ou como se comportar: elas falam muito alto, cospem no chão.

Eles interrompem a conversa, certo mamãe?! [Sara, a filha de 8 anos de Rachel que estava caminhando conosco e ouvindo a conversa]

Exatamente, Sara, eles entram na conversa - viu por que a mãe lhe diz para não interromper quando as pessoas estão conversando? Porque não é educado. Também [voltando para mim], eles não respeitam as filas, te empurram e nem pedem desculpas. Todos se aproveitam uns dos outros, pessoas sem instrução, sem cultura e moral! Tudo me estressa lá. Sempre foi assim. É por isso que saí de lá. Aqui eles são civilizados. São educados. Você não vê pessoas cortando fila, jogando lixo no chão, fofocando sobre a vida um do outro. Eles respeitam seu espaço, sua opinião, como você se veste. Eles são civilizados. Você viu aquelas senhoras (inglesas) sentadas ao nosso lado no pub? Você conseguia ouvir o que eles estavam falando? Não! Porque elas têm cultura, boas maneiras, educação algo que não temos.

Minha conversa com Rachel é típica de muitas outras que tive com migrantes brasileiros que se estigmatizam como tendo uma cultura e moralidade inferiores às dos europeus ocidentais. Ao fazer a 
divisão entre as pessoas "civilizadas", "educadas" "aqui" e "as pessoas sem instrução, sem cultura e moral" no Brasil, os comentários de Rachel destacam como a maneira pela qual os brasileiros se classificam depende os sistemas de classificação dos outros" (Skeggs, 1997, p.74). Em outras palavras, o relato de Rachel está embutido em representações históricas que estabeleceram moralmente, epistemicamente e esteticamente a inferioridade ontológica de não-europeus desde o colonialismo. Desde a chegada dos colonizadores portugueses, o Brasil e seus corpos, por exemplo, têm sido continuamente construídos em termos racializados, estigmatizados e sexualizados. Como mostra Beserra $(2007 ; 2000)$, a imagem inicial exótica do Brasil foi moldada pela crença europeia de que não havia pecado abaixo do trópico equatorial: o território praticamente desconhecido era imaginado como um paraíso na terra, sem leis, sofrimento, trabalho ou punição. No entanto, tais imagens e fantasias projetadas por europeus para o "resto do mundo" sempre foram construídas em torno da ideia de que o primitivismo já foi superado nos "países civilizados". Como Said (1978) ilustra, "primitivo", "selvagem", "imoral”, são termos que sempre colocam "o exótico" em uma posição que requer intervenção, ajuda ou dominação do civilizado. Essa representação, difundida na Europa no século XVII, tem sido continuamente reproduzida e ressignificada ao longo dos séculos, sendo também reforçada pelos próprios brasileiros, mesmo com o descrédito das ciências raciais no século $\mathrm{XX}^{3}$.

Na década de 1930, década considerada central para a modernização e industrialização brasileiras, o Estado, intelectuais e artistas tentaram criar uma nova ideia de nação para o Brasil. O povo brasileiro viveria e seria o produto de uma democracia racial, uma sociedade híbrida (Freyre, 1969). No entanto, a noção de "raça" e cultura híbrida também foi a base a partir da qual o Brasil e os brasileiros continuaram

3 Pensadores têm demostrado que, ao mesmo tempo em que a ciência e o conhecimento modernos
eram revolucionários, no século XVII, eles também eram reacionários, sendo usados como instru-
mentos para controlar aquelas populações vistas como "incivilizadas" (Hardt e Negri, 2000; Gros-
foguel, 2007; Gilroy, 2000). Nesse contexto, as ciências raciais desenvolveram explicações pseu-
docientíficas que demonstram como os não europeus não tinham "a biologia humana [correta]",
justificando a dominação racista nas colônias europeias (Grosfoguel, 2013, p. 83-84; veja também
Gilroy, 2000). Como Puwar (2004) discute, neste processo científico moderno de racialização, os
corpos e espaços não europeus foram representados como espaços selvagens e não civilizados, am-
bos precisando ser dominados, enquanto os corpos brancos foram associados com espírito e mente. 
Negociando diferenças culturais e de gênero essencializadas em um mundo global: Brasileiros em Londres.

a ser racializados e estigmatizados como não-modernos (Guimarães, 2002; Souza, 2012). O antigo mito do paraíso tropical do século XVII moldou e inspirou a criação de novos mitos, nos quais o Brasil, agora um país híbrido cultural e uma democracia racial, tornou-se um lugar de felicidade, cordialidade e sensualidade (Beserra, 2007). Como comenta Beserra (2007), esta imagem está fortemente representada no que mais tarde se tornaram os símbolos da 'identidade nacional brasileira' - futebol, carnaval e samba. No entanto, tais símbolos não estão apenas ligados ao primitivismo, mas trabalham para mercantilizar o corpo, o lugar e a "cultura" supostamente primitivos, na forma de música, dança, sexo e comida. Assim, a comparação de Rachel é produzida em diálogo com as representações e imaginações eurocêntricas (coloniais) de europeus e seus "outros" (Said, 1978), construídos através da dicotomia cartesiana de "mente" versus "corpo" (Puwar, 2004; Mills, 1997). Essas representações binárias já faziam parte dos imaginários de Rachel antes que a migração seja esclarecida quando ela diz: "É por isso que saí de lá (Brasil)".

Não estou sugerindo que não haja diferenças culturais entre brasileiros e europeus. Pelo contrário, estou destacando como os comentários de Rachel refletem o significado hierárquico atribuído historicamente pelos europeus a essas "diferenças". Nesses casos, a "diferença cultural" é essencializada, classificando grupos sociais com acesso diferenciado a riqueza, poder e privilégio - em relação um ao outro. Como Brah (1996) argumenta, "os valores e modos de comportamento estimados na sociedade são mais prováveis de serem aqueles que estão associados com os grupos dominantes na sociedade" (p.19). Esse grupo dominante, nos termos de Bourdieu (2004), seria o grupo que também é "culturalmente dominante” (cuja

4 A frase mais famosa de Descartes (1999 [1637]), "Penso, logo existo" ("Cogito ergo sum") baseia-se na afirmação de que "a mente é de uma substância diferente do corpo, que permite à mente ser indeterminado, não condicionada pelo corpo" (Grosfoguel, 2013, p.75). Essa afirmação era a essência da ideia iluminista da formação da humanidade universal moderna, na qual o homem racional (europeu) era visto como capaz de controlar o corpo (natureza): uma habilidade que corpos não-europeus eram marcados como não possuidores de. No entanto, o "Homem Universal racional" dos Cartesianos foi concebido não apenas em termos racializados, mas também de gênero e classe, que por sua vez foram usados para justificar desigualdades "raciais", de gênero e de classe (McClintock, 1995). A imagem do "homem universal" era um homem ocidental de classe alta (a mente civilizada). Aqueles corpos e espaços que não se enquadravam nessa "categoria intersectada" particular (homem branco, ocidental e de classe alta) não foram incluídos no "pacto social liberal / moderno", justificando sua desigualdade e dominação social devido a sua suposta inferioridade moral e intelectual (Mills, 1997; McClintock, 1995). 
cultura é "hegemônica" no campo) e que tem a capacidade de "definir a cultura em seu próprio padrão ou contestação" (p. 5).

Como consequência, como no caso de Rachel, todos os marcadores que poderiam ser tomados como parte de uma "cultura brasileira" - formas de se comportar, andar, falar - são qualificados como incivilizados / inferiores. Assim, o corpo aqui se torna "o lócus geométrico" de um estigma contra uma "cultura", sendo o principal marcador na articulação entre moralidade e poder. Engajando-se com Sayad (2004) e Bourdieu (1990), o corpo é tanto uma individualidade física quanto um produto social: ela carrega todos os marcadores inscritos de uma "cultura" (que também é moldada por gênero e classe): gestos, posturas, sotaque, linguagem, estilos, gostos ... e outras ações que "são pré-reflexivas" (Bourdieu, 1990). Nesse sentido, o desconforto que Rachel sente com a falta de boas maneiras dos brasileiros, a fala excessivamente alta e a indumentária imprópria tem seu equivalente no desconforto que ela experimenta na sua 'cultura nacional' - historicamente estigmatizada como desvalorizada e incivilizada.

\section{2 'Culturalizando' desigualdades sociais}

A cultura também é usada como um marcador importante quando os brasileiros em Londres comparam as desigualdades sociais entre o Brasil e a Europa Ocidental. A cultura inferior/incivilizada, imaginada como determinante na construção de corpos e comportamentos brasileiros, também é percebida como presente nas instituições sociais e políticas brasileiras, resultando na corrupção e desigualdade social brasileira. Isso pode ser visto em uma conversa que tive com Fabricio, na qual ele explicou a razão dele já saber que o Brasil ia perder para a Alemanha na semifinal da Copa do Mundo de 2014.

Claro que iríamos [perder para a Alemanha]. Eles se prepararam, desenvolveram sua equipe, anos de treinamento, e o Brasil não tem essa cultura de preparação, treinamento. Esta é a nossa cultura geral, há uma falta de razão aí. 
AMJ: O que você quer dizer?

Que temos a cultura errada. O problema começou quando os portugueses deram seus primeiros passos no Brasil. Eles impuseram seu sistema de vida. Duzentos anos atrás, o Brasil era tão rico quanto os EUA, mesmo nível de riqueza. Mas por que os norte-americanos se desenvolveram e nós não? Porque eles têm um sistema cultural diferente, o capitalismo anglo-saxão, e nós temos o português. Nós herdamos isso deles. É tudo sobre jeitinho: quem conhece quem, pular etapas, ninguém quer fazer as coisas da maneira certa. Por exemplo, não adianta dar uma casa para as pessoas das favelas porque elas vão fazer uma grande festa pra celebrar que elas têm uma casa e depois elas vão vende-la, queimar todo o dinheiro em coisas ruins e depois voltar a viver nas favelas. É por isso que o Brasil está cheio de falta de moradia, pobreza, violência, porque eles não são capazes de distinguir entre o certo e o errado. Nós nunca seremos um país moderno. Culpamos os políticos, mas o problema é a cultura, que é corrupta por natureza; é claro que nossos políticos serão corruptos.

AMJ: Você não acha que há corrupção aqui também?

Existe, mas aqui é uma pessoa aqui outra ali. Não faz parte da cultura deles. As coisas funcionam aqui.

Minha conversa com Fabricio traz luz à importantes pontos analíticos, pois está embutida em - e ajuda a ilustrar como - abordagens "culturalistas" têm sido usadas para discriminar o Brasil, seu povo e suas instituições. Em primeiro lugar, ao culpar os vestígios da cultura portuguesa (tradicional) por não permitir que o Brasil se torne uma nação moderna / racional, diferenciando-a das culturas anglo-saxônicas, Fabricio está posicionando a 'cultura' como uma variável determinante e independente na raiz das desigualdades sociais brasileiras. Ao fazê-lo, Fabrício está reproduzindo um relato racista e culturalista próximo ao de práticas políticas e reflexões teóricas que foram implementadas, reproduzidas e ressignificadas no Brasil desde a primeira república (1889-1929).

Durante a primeira república, quando os países ibéricos já haviam perdido seu lugar central no sistema mundial colonial para 
a "moderna" Grã-Bretanha, os brasileiros procuraram se "civilizar" através de políticas "raciais" que encorajavam a migração europeia (preferencialmente não-ibérica) (Seyferth, 1990; Schwarcz, 1993). Como parte do mesmo esforço "civilizatório", distanciaram-se da cultura tradicional portuguesa, pois os portugueses se tornaram estereotipados e ridicularizados como estúpidos e tradicionais, a fim de imitar costumes franceses e britânicos (Guimarães, 2002), aqueles mencionados por Fabricio. No entanto, aos olhos de Fabricio, o sistema cultural "herdado" dos portugueses ainda está impresso nos corpos brasileiros, o que não apenas explica por que o Brasil perdeu a partida de futebol, mas também porque o Brasil é corrupto, socialmente desigual e em desenvolvimento.

Segundo Fabricio e muitos outros brasileiros com quem conversei, essas "deficiências nacionais" podem ser atribuídas à falta de razão na cultura brasileira: "Eles não são capazes de distinguir entre o certo e o errado"; brasileiros não têm "uma cultura de preparação e treinamento". Os brasileiros teriam a cultura nepotista do jeitinho, na qual "pulam passos", ativando suas redes "pessoais" de relações sociais para conseguirem coisas através de favores e atos corruptos (DaMatta, 1981), ao invés de seguir a maneira racional / legal (burocrática) de "fazer as coisas certas" - o que Fabrício chama de "sistema cultural" do capitalismo anglo-saxão.

Como consequência, esse tipo de comportamento "corrupto" é incorporado às instituições políticas brasileiras. Por outro lado, na Grã-Bretanha, a corrupção é limitada a casos isolados e individuais, já que "não faz parte da cultura deles [anglo-saxônica]". Em tal discurso, Fabricio também está reproduzindo o mesmo preconceito (muitas vezes racista) encontrado tanto no senso comum quanto nas reflexões teóricas contemporâneas que tomam a corrupção como uma característica das sociedades "pré-modernas", "não-desenvolvidas" (Bernstein, 1971; DaMatta, 1981; Luhmann, 1995), devido às suas culturas 'híbridas', não totalmente 'modernas'.

Como demonstrado por Grosfoguel (2002), a discriminação do século 20, baseada na cultura, ao invés de 'raça' apenas, também foi legitimada por "abordagens acadêmicas que retratam altas taxas de pobreza entre pessoas de cor com relação aos seus valores 
culturais tradicional, inadequados, subdesenvolvidos e inferiores" (p.213). Nesse contexto, o chamado hibridismo exótico brasileiro também é frequentemente utilizado para explicar os vestígios percebidos das formas tradicionais de organização da sociedade e da política no Brasil, como a noção de personalismo (Holanda, 1995) e sua dimensão institucional, patrimonialismo (Faoro, 1998). Nesse discurso, ter uma cultura híbrida significa que o patrimônio cultural "tradicional" português ainda se encontra em corpos e instituições políticas brasileiras, resultando no determinismo das relações pessoais, nas formas como os brasileiros estruturam suas vidas sociais (personalismo) e políticas (patrimonialismo). Como argumenta Jessé Souza (2004), esses "remanescentes" de características "pré-modernas" têm sido utilizados e ressignificados por políticos e intelectuais para explicar a desigualdade e exclusão permanentes no "mundo periférico" 5 , uma vez que "os países, a sociedade e os indivíduos 'pré-modernos' são tomados como sujos, corruptos e potencialmente não confiáveis". Essa estratégia analítica mantém a presunção do "culturalismo essencialista", em que a cultura é percebida como homogênea, totalizadora e indiferenciada.

Dialogando com Souza (2004), muitos trabalhos teóricos sobre a América Latina, foram e são ainda explicita ou implicitamente marcados por essa presunção (ver Luhmann, 1995; DaMatta, 1981). Ao conjugar as terminologias modernas com as explicações culturalistas tradicionais, Luhmann (1995), por exemplo, supõe a existência em sociedades supostamente não desenvolvidas de redes de relações que obrigam a todos a participarem delas, transformando aqueles que são excluídos em 'un-persons' (não pessoas). DaMatta (1981), um dos antropólogos mais influentes do Brasil, segue uma lógica semelhante construindo o binário pessoa/não-pessoa, na qual a pessoa - por suas relações pessoais - pode fazer o que quiser, até mesmo ficar acima da lei, enquanto a não pessoa, o indivíduo, não tem privilégios na sociedade e é excluída por falta de relações pessoais (Souza, 2012). Essas redes de relações pessoais são consideradas centrais para o famoso "jeitinho brasileiro", ou a "pequena maneira

5 A teoria clássica da modernização das décadas de 1950 e 1960 (Bernstein, 1971) é a base principal dessa discussão. 
brasileira" de lidar com questões relacionadas, por exemplo, à lei e à burocracia, que depende de "quem conhece quem".

Portanto, compreendendo a corrupção brasileira e as desigualdades sociais ligadas à sua cultura, Fabricio está reproduzindo e ressignificando representações eurocêntricas, muitas vezes ainda racializadas, que justificam a "posição periférica" do Brasil no sistema mundial. Ao mesmo tempo, essa ligação obscurece a (re)produção contínua de desigualdades e hierarquias ('raciais', de classe, de gênero) dentro desse sistema e as consequências simbólicas e materiais do colonialismo para aqueles tomados como 'corpo' (não europeu). (Mills, 1997; Grosfroguel, 2007). Naturalizar a desigualdade social e a produção de pobreza como um fenômeno de massa em países periféricos, como uma herança "pré-moderna" e "personalista", não nos permite compreender como tais fenômenos resultam de processos de modernização em larga escala. que foram gradualmente implantados nessas sociedades como resultado da expansão capitalista mundial (Souza, 2012).

\subsection{Gênero na divisão corpo versus mente}

O gênero, cruzado com a cultura e a "raça", é outro marcador importante usado pelos brasileiros em Londres para se comparar aos europeus ocidentais e britânicos. É muito comum ouvir brasileiros em Londres, tanto mulheres quanto homens, reproduzir e ressignificar o estigma de gênero, raça e sexualidade contra as mulheres brasileiras em um novo contexto, ao mesmo tempo em que valorizam as mulheres britânicas (e "sua branquidade"), como podemos ver com Adriano:

Mulheres brasileiras, apenas para sexo. Eles são todas prostitutas aqui. Veja como elas se comportam nas baladas, como elas se vestem. Elas só se relacionam com você se puderem obter algo, como um passaporte [europeu], e você será corno [traído]. As mulheres britânicas são as melhores para mim, no mundo. Desde criança eu costumava assistir TV e vê-las, todas bonitas, olhos claros, com seu sotaque sexy e encantador. Comparar britânicas e brasileiras seria um massacre, em cultura, estudo, comportamento. Mulheres inglesas, se você as vê no metrô, percebe como elas são estudadas, 
a quantidade que elas sabem sobre a atual situação econômica e política do país. Elas são politizadas; cultas, civilizadas. Elas têm uma mente que considero superior às outras raças.

AMJ: Você já saiu com uma mulher britânica?

Ainda não, porque não conheço nenhuma mulher britânica. Eu conheci uma em um pub onde eu costumava trabalhar, mas era difícil ter algo com ela porque eu não conseguia entender o seu sotaque. Mas meu objetivo é conseguir meus documentos [se regularizar], ir para a universidade, casar com uma britânica e ter uma família.

Como podemos ver, a representação de Adriano sobre as mulheres brasileiras - prostitutas que lhe traem - reproduz pressupostos históricos de (hiper) sexualidade e desejo sexual 'racial' que também estão no cerne dos processos de estereótipos e da construção e representação de diferença racial e de gênero (Alexander e Knowles, 2005). O empreendimento eurocêntrico histórico de dividir continuamente a população mundial entre culturas civilizadas e valorizadas (mente) e culturas não civilizadas (corpos) também é construído por meio de pressupostos sexuais e de gênero (ver Connel, 1998; Collins, 2004; Nagel, 2001; Stolke, 2006). Como Joane Nagel (2001) argumenta, "representações sexuais e degradação do "outro" racial, étnico e nacional e a regulação do comportamento sexual de corpos são mecanismos importantes pelos quais fronteiras raciais foram “construídas, mantidas e defendidas", desde a colonização (p.123). Verena Stolke (2006), por exemplo, mostra como desde a colonização ibérica tem havido uma produção de representações essencializadas de mulheres, nas quais mulheres brancas europeias são representadas como boas esposas e mães, enquanto mulheres indígenas, negras ou mistas, de ex-colônias, são vistas como prostitutas pecaminosas com uma hiper sexualidade.

A produção de fronteiras racistas e estigmatizadas através do entrelaçamento de "raça", nacionalidade, etnia e presunções sexuais tem sido particularmente aparente no caso das mulheres brasileiras. Pesquisadoras feministas brasileiras mostraram como a imagem exótica, erótica e sensual das mulheres brasileiras foi disseminada 
e mercantilizada pela indústria do turismo brasileiro (Gomes, 2013), a indústria internacional de pornografia (Beserra, 2007), a indústria internacional de turismo sexual (Piscitelli, 2008) e outros mercados de exotismo cultural, 'racial' e sexual - como foi o caso, por exemplo, da marca Adidas vendendo camisetas que promoviam imagens sexualizadas de mulheres brasileiras durante a Copa do Mundo de 2014, no Brasil (Boadle, 2014) ${ }^{6}$. Essa imagem estigmatizada está presente em muitas narrativas de brasileiros ao comentar sobre os comportamentos e corpos de mulheres brasileiras em Londres, como ilustra a crítica de Adriano acima. Como Sayad (2004) destaca, a crítica mais violenta e direta à migração é contra a população feminina e seus corpos. O corpo da migrante mulher é "objeto de uma intensa e dramática catequese e vigilância “, que se concentra na maneira como "elas se vestem, formas de se apresentar, falar e se comportar em público" (p.117). Essa vigilância é realizada pela sociedade de origem, pela sociedade de acolhimento e pelos próprios migrantes. Isso se reflete na fala de Adriano ao fazer referência ao "modo como se comportam e vestem", bem como em sua afirmação de que ele se relacionaria com uma mulher brasileira "só para sexo" porque "são todas prostitutas aqui". Seu objetivo é se casar com uma britânica, culta e respeitável, bonita, com um "sotaque sexy e encantador" e "olhos claros". Aqui, noções racistas e estigmatizadas de cultura/ moralidade, sexualidade e beleza (branca) se cruzam em suas justificativas para desdenhar as mulheres brasileiras e desejar mulheres britânicas. Corpos femininos respeitáveis, como notado por acadêmicas feministas, são historicamente representados como brancos, heterossexuais e de classe média (ver Skeggs, 1997; Davis, 1995).

\subsection{O macho (hipersexual) e o príncipe (civilizado)}

A conexão entre beleza, branquidade e cultura (moralidade) também é comum entre as mulheres brasileiras quando uma comparam homens brasileiros e britânicos. Estudiosos pós-coloniais mos-

6 Durante a Copa do Mundo de 2014 no Brasil, a Adidas teve que se desculpar e parar de vender duas camisetas para o evento, já que havia sexualizado imagens de mulheres brasileiras. Em uma camiseta, o logotipo tinha uma mulher de biquíni na frente com as palavras "Lookin 'to score" (procurando para marcar) e a outra um coração em formato de fio dental (Boadle, 2014). 
traram como as construções históricas da masculinidade não-branca são inseparáveis das noções de hipersexualidade (ver Collins, 2004; Young, 2005). Dialogando com essas representações, muitas brasileiras também afirmam que não entrariam em um relacionamento com um brasileiro em Londres. Como Amanda me disse, "os homens brasileiros são machistas (sexistas) e você não pode confiar neles". Segundo ela, devido ao seu alto desejo sexual, "os brasileiros vão trair você". Por outro lado, ela descreve o encontro com um homem britânico:

É como um sonho, como conhecer um príncipe: loiro, alto, olhos azuis, não machista. Eles pagam a conta no restaurante. Eles pegam o cardápio e perguntam se você quer beber um sauvignon ou um pinot noir? Peixe ou carne?

Com Adriano e Amanda, podemos ver como os brasileiros reproduzem os relatos racistas de "aparência" interseccionados com a moral para explicar por que eles não querem se relacionar intimamente com os brasileiros e por que desejam um parceiro britânico. Aqui, aparência importa porque as representações históricas dos corpos são cruciais para a constituição do preconceito; emprestando de Brah, "os poderes racializados operam nos e através dos corpos" (Brah, 1996, p.3). Patricia Collins (2004) argumenta que tais representações históricas racistas e estigmatizadas, que são reproduzidas na mídia, nos filmes e na cultura popular, permitem a ideia contínua de não-brancos como corpos "hipersexuais" (p.207), "sexualmente promíscuos e se envolvem em práticas sexuais que se assemelham às dos animais "(p.351). Tais representações se refletem nos argumentos respectivos de Adriano e Amanda, nos quais "mulheres brasileiras são prostitutas" e "homens são machistas e não confiáveis". Essas representações, além disso, resultam em desejos racializados, como Adriano dizendo que ele cresceu admirando as mulheres inglesas que assistia na TV, ou Amanda descrevendo o encontro de um homem alto, branco e britânico como "um sonho" e "como conhecer um príncipe". Esse desejo, por sua vez, é baseado em representações que permitem relatos contraditórios - como a descrição de Adriano 
sobre mulheres britânicas cultas, das quais ele nunca teve a chance de conhecer uma, ou a afirmação de Amanda de que "o príncipe" não é machista porque paga a conta do restaurante.

\section{NEGOCIANDO "CULTURA BRITÂNICA" E NAVEGAN- DO A "BRASILIDADE"}

Nesta seção, argumento que os brasileiros estão constantemente negociando e reenquadrando a "cultura britânica" e a "brasileira" em contextos específicos, por meio de estratégias de reconhecimento e subversão das representações essencializadas da cultura brasileira. Como Sayad (2004) observa, a primeira estratégia 'envolve o reconhecimento dos critérios de julgamento que baseiam a 'identidade' em uma fundação legítima', enquanto a segunda ataca 'relações de poder simbólicas, na busca de inverter a escala de valores que autoriza a estigmatização, ao invés de questionar as características/categorias estigmatizadas" (p.256-7). Os brasileiros usam essas estratégias de subversão quando enfrentam situações em que tentam minar o estigma contra os brasileiros ou quando "ser brasileiro" adquire um significado simbólico positivo. No entanto, no processo, eles tendem a re-inverter a escala de valores que estruturam a estigmatização, dando um valor negativo à "cultura britânica" e um valor positivo para a "brasileira". Dialogando com Brah (1996), o racismo e os preconceitos não impõem "bipolaridades simples de positivo e negativo, superioridade e inferioridade", ao contrário, "habitam simultaneamente espaços de profunda ambivalência, admiração, inveja e desejo" (p.15). Assim, os brasileiros estão constantemente navegando em tais espaços de ambivalências, onde suas narrativas são muitas vezes contraditórias. Isso só é possível, defendo, porque "raça" e "etnicidade" são "categorias de poder" sociais que são feitas e refeitas por pessoas no nível cotidiano, realizadas em encontros mundanos entre indivíduos, bem como na interface entre as pessoas e estrutura. Em outras palavras, elas são parte de um "sistema de significados sociais e classificações culturais, que é criado e mantido através de relações de poder e hierarquia, mas que muda com o tempo e que pode ser contestado e subvertido" (Alexander e Knowles, 2005, p.11). 
Negociando diferenças culturais e de gênero essencializadas em um mundo global: Brasileiros em Londres.

\subsection{Negociando o encantamento}

Como discutido anteriormente, os brasileiros parecem encantados com uma imagem da cultura britânica como civilizada e racional, em contraste com sua contraparte da cultura brasileira como incivilizada. No entanto, essas imagens também estão abertas para negociação. O tempo é um fator importante para os brasileiros na negociação e reformulação da "cultura britânica" e da "brasilidade". Com o passar do tempo, eles descobrem que o Reino Unido não é tão perfeito quanto imaginavam. Além disso, a representação de brasileiros e britânicos tende a ser negociada, especialmente quando brasileiros narram encontros diários com britânicos nos quais tentam derrubar o estigma associado à "cultura brasileira". Essas tentativas de subversão são marcadas por uma série de contradições e manipulações, que não necessariamente excluem seus relatos anteriores de distanciamento da "cultura brasileira". Pelo contrário, eles coexistem, muitas vezes aparecendo na mesma entrevista, como foi o caso de Jacob, um trabalhador de tecnologia informacional de 49 anos.

No início de nossa entrevista, Jacob me disse que, ao viver no exterior, percebeu que "nunca teve a cultura brasileira não civilizada", alegando que "nasceu no país errado". Ele afirmou que se sentia "mais em casa" quando morou na Itália por alguns meses - o país onde seus avós nasceram. No entanto, ao final de nossa entrevista, sua percepção mudou quando ele começou a me contar sobre casos de discriminação do povo britânico no trabalho. Embora Jacob pensasse que ele nasceu no país errado, ele não conseguiu se livrar de sua "origem brasileira" e de suas "consequências" estigmatizadas.

Antes de viver e trabalhar aqui, eu costumava ter uma visão diferente deles. Eu pensei que eles fossem mais britânicos do que realmente são [risos]. Por exemplo, no trabalho, achei que não iria sofrer com a falta de organização e eficiência que temos no Brasil, mas é o mesmo aqui. Achava que eles fossem mais formais, bonitos, parecem ser mais organizados, mas não são. Toda essa formalidade é falsa e eles são muito ruins no trabalho. Eles são muito fracos, ineficientes, rígidos, não pensam fora da caixa. Nós trabalhamos melhor que eles. Essa coisa que eles não fofocam também, não é verdade. Eles 
fofocam muito, mas fazem isso com estilo, tomando chá [risos]. E eles não aceitam receber ordens de uma pessoa não britânica e eu tenho muitos exemplos que posso dar aqui de minhas experiências trabalhando com eles. Eles ainda têm essa posição imperialista com os não-britânicos. Sou gerente de projetos e, em muitos casos, eles não aceitam receber ordens de um brasileiro ou trabalhar com outras pessoas em nossa equipe, como os indianos.

Discriminação no local de trabalho era um tema muito comum nas falas de brasileiros que trabalham em empregos altamente qualificados. Ao descrever situações discriminatórias, eles sempre relativizaram sua representação inicial do povo britânico, resultando em críticas à cultura britânica e valorizando a "brasilidade". Como Jacob, muitos afirmaram que, com o passar do tempo em Londres, eles começaram a perder a ideia encantada inicial de "povo britânico" como seres racionais, organizados, formais e individualistas: eles "fofocam", "formalidade é falsa" e eles não são organizados ou eficientes. Aqui, podemos ver, em primeiro lugar, como "cultura" é um processo, um terreno no qual os significados sociais são produzidos, apropriados, interrompidos e contestados (Brah, 1996; Collins, 2004). Em segundo lugar, vemos como as especificidades culturais são similarmente construídas como modalidades flexíveis dentro de uma multiplicidade de locais, estruturas e relações de poder, nas quais o significado dado aos sistemas de significação pode mudar ao longo do tempo e através de deslocamentos estruturais - sociais, econômicos e políticos - (Brah, 1996), bem como no contexto situacional.

No entanto, ao criticar os trabalhadores britânicos na tentativa de subverter o estigma ligado à "cultura / povo brasileiro" e valorizar-se, muitos dos meus entrevistados tendem, mais uma vez, a essencializar as categorias relacionais de diferença - nesse caso, 'cultura britânica e brasileira' - em uma disposição binária de 'corpo / mente ', mas com a escala de valor invertida. O corpo é tomado como positivo e a mente como negativo. Os trabalhadores britânicos, associados à mente, são descritos pelos brasileiros como "fracos", "rígidos", "quadrados" e "presos dentro de uma caixa", o que refletiria, como me disse Leonardo, um outro trabalhador altamente 
qualificado, sua "cultura formal / racional muito treinada". Por outro lado, os brasileiros (corpo) são apresentados como positivos por causa de "nossa cultura flexível, não muito racional", criando, como Leonardo me disse, "trabalhadores árduos, flexíveis, criativos que sempre encontram uma maneira de resolver um problema" - "o jeitinho brasileiro de lidar com as coisas".

Assim, quando os brasileiros tentam romper com as hierarquias, o mesmo "jeitinho brasileiro", normalmente citado como as características que não permitem que o Brasil se torne um país desenvolvido moderno, recebe um valor positivo na diferenciação dos trabalhadores brasileiros em relação aos britânicos. Como Bourdieu (1991) destaca, propriedades simbólicas, mesmo as mais negativas, podem ser usadas estrategicamente de acordo com os interesses materiais e simbólicos de seu portador. Assim, destacar os aspectos positivos do jeitinho não é apenas uma forma dos brasileiros afirmarem seu valor como trabalhadores, mas também um meio de atacar as relações simbólicas de poder que justificam a discriminação contra eles.

\subsection{Negociando o príncipe e o macho}

Os brasileiros também tendem a renegociar a brasilidade e cultura britânica ao falar sobre seu relacionamento íntimo com os britânicos em casa. Nesses casos, as mesmas noções de cultura brasileira como 'corpo' em contraste com a 'mente' britânica que resultaram em noções opostas de masculinidades - 'o machista' brasileiro em contraste com o 'príncipe’ britânico, discutido anteriormente, são ressignificadas a fim de explicar os problemas em seus relacionamentos. Isso ficou claro, por exemplo, quando Amanda explicou por que ela terminou o relacionamento com seu marido britânico.

Eu trabalho cuidando de duas crianças britânicas e vejo sua educação. É tão reprimido: você precisa falar em voz baixa, pedir desculpas por tudo, não pode tocar nas pessoas. Então, não é polidez real, é obrigação, treinamento. Eles estão cheios de barreiras, individualistas. Eles são pessoas tristes. Não há emoção. Então, quando se encontram com brasileiros, ficam malucos porque somos o oposto do que eles 
são. Nós temos emoção, fogo, somos sensuais. É por isso que eu terminei com meu ex-marido. Eu não vou negar isso, eles são como um príncipe para nós, mas o príncipe é frio [risos]. Além do fato de que eles bebem demais para se libertarem, eles são sexualmente restritos demais, preguiçosos. Os brasileiros te agarram, eles têm fogo.

Quando conheci Amanda, ela havia dito que evitava relacionamentos com brasileiros, enquanto conhecer um homem europeu era como conhecer um príncipe. No entanto, ao explicar mais tarde por que ela rompeu com o marido britânico, Amanda começou a usar uma dicotomia essencializada de "cultura brasileira e britânica", re-invertendo a hierarquia de valor. Aqui, a representação da sociedade britânica e seu povo como "mente" é ressignificada como "individualistas", "cheios de barreiras", "frios", sem emoção e "tristes", bem como "sexualmente rígidos e preguiçosos". Dentro dessa lógica, as representações de 'brasilidade' como 'corpo', resultando em uma masculinidade hipersexual, que ela anteriormente apresentava como um problema, afirmando que os homens brasileiros eram sexistas e indignos de confiança, também são ressignificadas como algo positivo: 'brasileiros te agarram, eles têm fogo'.

Além disso, Amanda também reforça o estereótipo das mulheres brasileiras - como emocional, ardente e sexy, com o poder de fazer os britânicos "enlouquecerem" -, para valorizar a si mesma. Assim, ela usa a mesma representação estigmatizada que muitas mulheres brasileiras - incluindo ela mesma - apontam como facilitadoras da caracterização (negativa) das mulheres brasileiras como “promíscuas". De fato, na grande maioria de minhas entrevistas, as mulheres brasileiras mencionaram que o estereótipo sexualizado das mulheres brasileiras no exterior era um problema, ao mesmo tempo em que se retratavam como mais sexy e mais eroticamente atraentes do que as mulheres britânicas. Isto é semelhante à pesquisa sobre mulheres brasileiras em Portugal (Malheiros e Padilla, 2014; Gomes, 2013) e nos EUA (Beserra, 2000), que também mostra que as mulheres brasileiras, em algum momento, foram confrontadas com imagens negativas de exotismo, que as enquadram como sexy, vulgar, exótica e, como afirma Gomes, um “corpo sempre disponí- 
Negociando diferenças culturais e de gênero essencializadas em um mundo global: Brasileiros em Londres.

vel" (2013, p.871). Esses estudos também destacam como, ao mesmo tempo em que essas mulheres tentam criticar essas representações, também tentam frequentemente transformar essas imagens exóticas negativas em um recurso positivo, promovendo uma ideia de "beleza natural brasileira e sex appeal", nas indústrias do sexo (Piscitelli, 2008) e da beleza (Malheiros e Padilla, 2014), bem como no 'mercado do casamento' (Beserra, 2000).

\subsection{Deslocando afiliações}

O estereótipo sexualizado / exótico dos brasileiros também é negociado quando eles tentam empoderar-se nas interações com os não brasileiros. Durante meu trabalho de campo em bares, casas noturnas e festas domésticas, notei que os brasileiros estavam constantemente navegando através de mudanças de afiliação ou distanciamento da "cultura brasileira", dependendo do significado que esta adquiri durante a interação social com brasileiros e não brasileiros. No entanto, muitos momentos de 'reconhecimento' da 'cultura brasileira' também resultaram em situações em que os brasileiros reforçaram o estereótipo sexualizado/exótico que anteriormente criticavam. Demonstrar ou ensinar a conhecidos britânicos como dançar sexualmente, ou dizer que os brasileiros, ao contrário dos britânicos, "são bons de cama" porque "sabem como mover seus corpos", por exemplo, são exemplos típicos. Nesses casos, as mulheres brasileiras reforçam estereótipos em situações em que reconheciam que poderiam usar as representações eróticas / exóticas de seu corpo como potencial empoderamento (Lorde, 1984) - em outras palavras, em situações em que tais representações poderiam funcionar como um capital simbólico, proporcionando-lhes ganhos, sejam eles materiais ou simbólicos. No entanto, não foram apenas as mulheres brasileiras que eu observei fazendo isso, mas também os homens, como foi o caso de Manoel.

Manoel sempre reclamava dos locais de lazer dos brasileiros, mesmo antes de ir a esses lugares, pois lá encontraria tudo o que estava tentando se distanciar: a "cultura brasileira incivilizada". Eu estava com ele na primeira vez em que foi ao Guanabara, uma casa noturna brasileira no centro de Londres, porque seu amigo cantaria 
lá. Uma vez no evento, Manoel só falava inglês com os trabalhadores, mesmo com os garçons que eram brasileiros. Além disso, ele continuava reclamando sobre como as pessoas eram ignorantes, empurrando umas às outras o tempo todo e sobre a música. No entanto, quando seu amigo começou a cantar, Manoel percebeu que todos, especialmente as mulheres não brasileiras, estavam tentando cantar e dançar ao som da música brasileira. Ele então começou a dançar e cantar junto, perto das mulheres não brasileiras. Neste ponto, cantar e dançar corretamente se tornou uma forma de capital simbólico. Manoel acessou sua "exótica brasilidade" exibindo sua "corporalidade brasileira", ganhando a atenção das mulheres não brasileiras ao seu redor. Depois de dançar com elas, ele se virou para mim e comentou: "Aqui (Guanabara) é o único lugar em Londres que, às vezes, ser brasileiro pode ser bom".

Assim, as mesmas características da "corporalidade brasileira" (falar em voz alta, dançar sensualmente, empurrar pessoas e assim por diante) que são identificadas como "negativas" por aqueles que são críticos dos lugares brasileiros de lazer, são ressignificadas quando "ser brasileiro" é tomado como algo positivo. As mesmas pessoas começam a manipular as mesmas características que criticam, seja como forma de se distinguirem, seja como um mecanismo defensivo em resposta às situações de preconceito contra si mesmas - como no exemplo de Jacob descrito acima. No entanto, 'exotizar' a 'brasilidade' pode realmente empoderar o sujeito em interações dentro do campo, funcionando como um capital simbólico (Sayad, 2004) ao inverter a escala de valor do estigma - positivamente essencializando (e homogeneizando) os brasileiros como 'corpo', como quente, apaixonado e sexy, e negativamente essencializando o britânico como "mente", como frio, rígido e fraco. No entanto, ao fazer isso, os brasileiros podem acabar reificando o mesmo discurso que justifica as desigualdades no Brasil, e sua posição "periférica" no sistema mundial, assim como os relatos sexualizados que estigmatizam os brasileiros, especialmente as mulheres brasileiras. Assim, o seu agenciamento individual resulta numa confluência perversa com as narrativas e discursos que subordinam os brasileiros sob o termo exótico - perverso porque, ao obter ganhos individuais através 
Negociando diferenças culturais e de gênero essencializadas em um mundo global: Brasileiros em Londres.

da mobilização do "exótico" como capital simbólico, legitimam as mesmas características historicamente utilizadas para estigmatizar os brasileiros e justificar as desigualdades no sistema mundial.

\section{CONCLUSÃO}

Respondendo a apelos entre acadêmicos para investigar processos de migração transnacional além da suposta produção de "semelhanças/comunidades étnicas" (ver Bhambra, 2013; Kosnick, 2009; Grosfoguel et al, 2014), trabalhei meus dados em diálogo com uma variedade de tradições teóricas, incluindo feminismo e estudos pós - e de-coloniais, examinando as experiências migratórias brasileiras em relação aos legados coloniais e as múltiplas distinções que existem entre os migrantes. Analisei como os brasileiros, em vez de se afiliarem a categorias específicas de maneiras que resultam em uma valorizada "semelhança cultural" percebida, reinventam e contraditoriamente negociam representações culturais, bem como "raciais" e de gênero, ao falarem ou interagirem com brasileiros, bem como com europeus ocidentais / britânicos. Os brasileiros tendem, em primeiro lugar, a estigmatizar o Brasil e seu povo por meio da reprodução e ressignificação de narrativas de "cultura" e "raça", historicamente reproduzidas desde a colonização. A "cultura brasileira" foi narrada como uma cultura inferior, que resulta na constituição de corpos imorais, incivilizados e sem educação. Por outro lado, os europeus ocidentais são corpos educados, belos e civilizados, vivendo em um país com instituições racionais e modernas. Tais representações binárias são também moldadas por pressupostos de gênero, que produzem representações sexualizadas de mulheres e homens brasileiros. No entanto, em contextos específicos, os brasileiros também reformularam as representações de "cultura britânica e brasileira", navegando por mudanças frequentemente contraditórias de afiliação e narrativas de subversão, nas quais "ser brasileiro" tem um valor positivo em sua distinção da cultura britânica.

Com base na vida dos brasileiros em Londres, é possível ver como a experiência da migração é repleta de contradições, constrangimentos e ansiedades que as pessoas precisam administrar constan- 
temente, em diálogo com marcadores sociais historicamente arraigados e representações de modos de ser valorizados e não valorizados. Este foi o caso aqui com as maneiras pelas quais os brasileiros se envolveram com representações essencializadas da "cultura brasileira", bem como ao lidar com racismo e / ou preconceito direto em Londres. Como Bhambra (2013) observa, qualquer teoria que busque abordar a questão de como vivemos no mundo "não pode tratar como irrelevante a configuração histórica desse mundo" (p.307). É somente levando em conta a constituição do global colonial, e seus “outros", que podemos entender como o presente global (móvel) e seus "outros" passaram a ser constituídos como tal. Tal análise é frequentemente ausente dos estudos transnacionais. $\mathrm{O}$ exame dos legados coloniais permitiu-me, assim, desenvolver uma análise multidimensional das formas como os migrantes criam afiliações e/ou dissociações através de (essencializadas e estigmatizadas) diferenças culturais, "raciais" e de gênero.

\section{REFERÊNCIAS}

ALI, S. Uses of the exotic: Body, narrative, mixedness. In: Alexander, C. and Knowles, C. (Org). Making Race Matter: Bodies Space \& Identity. Basingstoke: Palgrave Macmillan, 2005, p. 153-171.

ANDERSON, B. Us and Them? The Dangerous Politics of Immigration Control. Oxford: Oxford University Press, 2013.

ANTHIAS, F. and YUVAL-DAVIS, N. Racialized boundaries: race, nation, gender, colour and class and anti-racist struggle, London: Routledge, 1992.

APPADURAI, A. Modernity at large: cultural dimensions of globalization, Minneapolis: University of Minnesota Press, 1996.

ASSIS, G., CAMPOS, E., SIQUEIRA, S. As redes sociais na configuração da migração internacional para os Estados Unidos, In: 34th annual conference of ANPOCS, Editora ANPOCS, v. 1, p.1-25, 2010

BACK, L. and SINHA, S. Migrant City, London, Routledge, 2018.

BERMUDEZ, A. The transnational political practices of Colombians in Spain and the United Kingdom: politics 'here' and 'there', Ethnic and Racial Studies, v.33, n.1, p. 75-91, 2010 
Negociando diferenças culturais e de gênero essencializadas em um mundo global: Brasileiros em Londres.

BERNSTEIN, H. Modernization theory and the sociological study of development, Journal of Development Studies, v.7, n.2, p.141-160, 1971.

BESERRA, B. Sob a sombra de Carmen Miranda e do carnaval: brasileiras em Los Angeles, Cadernos Pagu, v.28, p.313-344, 2007. (2000) Brazilians in Los Angeles: Imperialism, Immigration, and Social Class, Doctoral Thesis, University of California Riverside: California.

BHAMBRA, G. K. The Possibilities of, and for, Global Sociology: A Postcolonial Perspective, Political Power and Social Theory, 24: 295-314, 2013.

BOADLE, A. World Cup T-shirts pulled by Adidas after Brazilian tourism board complain they 'encourage prostitution', Daily Mail Online (25 February, 2014): http:/www.dailymail.co.uk/sport/worldcup2014/ article-2567884/World-Cup-T-shirts-pulled-adidas-Brazil-touristboard-complaints.html (last accessed 11 September, 2016).

BOURDIEU, P. Introduction. In: Sayad, A. The Suffering of the Immigrant, Cambridge: Polity, 2004 . Language and Symbolic Power, Cambridge: Polity Press, 1991. . Logic of Practice, Oxford: Polity, 1990. . Distinction: A social critique of the judgement of taste, Cambridge, MA: Harvard University Press, 1984.

BRAH, A. Cartographies of diaspora, London: Routledge, 1996.

COLLINS, P. H. Black sexual politics: African Americans, gender, and the new racism, New York: Routledge, 2004.

CONNELL, R. W. Masculinities and Globalization, Men and Masculinities, v.1, n.1, p.3-23, 1998.

DAMATTA, R. Carnavais, malandros e heróis, Rio de Janeiro: Zahar, 1981.

DATTA, K. Transforming South-North relations? International migration and development, Geography Compass, v.3, n.1, p.108-134, 2009.

DAVIS, A. 'I Used to be Your Sweet Mama: Ideology, Sexuality and Domesticity in the Blues of Gertrude "Ma" Rainey and Bessie Smith', In: GROSZ, E. and PROBYN, E (eds.) Sexy Bodies: The Strange Carnalities of Feminism, London: Routledge, p. 231-66, 1995.

DESCARTES, R. Discurso do Método, Os pensadores, São Paulo: Abril Cultura, 1999 (1637). 
DJELIC, M. L. and S. QUACK. Transnational Communities: Shaping Global Economic Governance, Cambridge: Cambridge University Press, 2010.

EVANS, Y., TONHATI, T., Dias, G., BRIGHTWELL, G., SOUZA, A., SHERINGHAM, O. and SOUZA, C. For a better life: Brazilians in London, 2011, available at: http://geblondon.files.wordpress. com/2011/03/por-uma-vida-melhor-geb-2011.pdf (last accessed 3 September 2015).

LORDE, A. Uses of the Erotic: The erotic as Power, In: Sister Outsider: Essays and Speeches. Freedom, CA: Crossing Press, 1984, p.53-59.

FAORO, R. Os Donos do Poder - Formação do Patronato Político Brasileiro, São Paulo: Globo, 1998.

FREYRE, G. Novo mundo nos trópicos, São Paulo: Nacional/EDUSP, 1969.

GILROY, P. Between Camps, London: Penguin Books, 2000.

. The Black Atlantic: Modernity and Double Consciousness, London: Verso, 1993.

GOMES, M. S. [Des][Re]Construcciones del Imaginario Social 'Mujer Brasileña' en los discursos turísticos sobre Brasil en Portugal, Estudios y Perspectivas en Turismo (En Línea), v.22, p.216-234, 2013.

GOZA, F. Redes sociais e a integração de brasileiros no Canadá e nos Estados Unidos, In: MARTES A. C. B., FLEISCHER, S. (ed.) Fronteiras cruzadas: etnicidade, gênero e redes sociais, São Paulo: Paz e Terra, 2003, p.263-288.

GROSFOGUEL, R. The Structure of Knowledge in Westernized Universities: Epistemic Racism/Sexism and the Four Genocides/ Epistemicides of the Long 16th Century, Human Architecture: Journal of the Sociology of Self-Knowledge, v.11, n.1, p.73- 90, 2013.

. Decolonizing Post-Colonial Studies and Paradigms of PoliticalEconomy: Transmodernity, Decolonial Thinking, and Global Coloniality, Transmodernisty: Journal of Peripheral Cultural Production of the Luso-Hispanic World, v.1, n.1, 2011, available at: http://dialogoglobal.com/texts/grosfoguel/Grosfoguel-DecolonizingPol-Econ-and-Postcolonial.pdf (last accessed 5 January 2015).

. Dilemas dos estudos étnicos norte-americanos: multiculturalismo identitário, colonização disciplinar e epistemologias descoloniais, Ciência e cultura, v.59, n.2, p.32-35, 2007.

. Colonial Difference, Geopolitics of Knowledge and Global Coloniality in the Modern/Colonial Capitalist World-System, Review, v.25, n.3, p.203-24, 2002. 
Negociando diferenças culturais e de gênero essencializadas em um mundo global: Brasileiros em Londres.

GROSFOGUEL, R. OSO, L., and CHRISTOU, A. () 'Racism', intersectionality and migration studies: framing some theoretical reflections', Identities, v.22, n.6, p.635-652, 2014.

GUIMARÃES, A. S. Classes, raças e democracia, São Paulo: Editora 34, 2002.

HALL, S. Representation: cultural representations and signifying practices, London: Sage, 1997.

HARDT, M and NEGRI, A. Empire, London: Harvard Press, 2000.

HOLANDA, S. B. Raízes do Brasil (26 ed.), São Paulo: Companhia das Letras, 1995.

KOSNICK, K. 'Out on the Scene: Queer Migrant Clubbing and Urban Diversity', Ethnologia Europaea, v.38, n.2, p.19-30, 2009.

LEVITT, P. The transnational villagers, Berkeley and London: University of California Press, 2001.

LEVITT, P. and JAWORSKY, B. N. Transnational migration studies: past developments and future trends, Annual Review of Sociology, v.33, n.1, p.129-156, 2007.

LIGHT, I., and GOLD, S. J. Ethnic Economies, San Diego CA: Academic Press, 2000.

LIZARDO, O. Can cultural capital theory be reconsidered in the light of world polity institutionalism? Evidence from Spain, Poetics, v.33, p.81-110, 2005.

LUHMANN, N. Inklusion und Exklusion, Soziologische Aufklärung, 6, Opladen: Westdeutscher Verlag: 237-264, 1995

MCILWAINE, C., COCK, J. and LINNEKER, B. No longer invisible: the Latin American community in London, London: Queen Mary, University of London; Latin American Womens' Rights Service; Trust for London, 2011.

MALHEIROS, J. and PADILLA, B. Can Stigma become a resource? The Mobilization and Aesthetic Corporal Capital of Female Immigrant Entrepreneurs from Brazil, Identities: Global Studies in Culture and Power, v.22, n.6, p.687-705, 2014.

MARGOLIS, M. Na virada do milênio: a emigração brasileira para os Estados Unidos, In: MARTES, A. C. B., and FLEISCHER, S. (ed.) Fronteiras cruzadas: etnicidade, gênero e redes sociais, São Paulo: Paz e Terra, pp.51-72, 2003.

MARTES, A. C. New Immigrants, New Land: A study of Brazilians in Massachusetts, Gainesville: University Press of Florida, 2011. 
. Raça e Etnicidade - Opções e Constrangimentos, In: MARTES. A. C. B, and FLEISCHER, S. (eds.) Fronteiras Cruzadas: Etnicidade, Gênero e Redes, Petropolis, RJ, Brazil: Editora Paz e Terra, 2003. p.73-98.

MARTES, A. C, and FAZITO, D. Solidarity and Social Networks, Economic Sociology - The European electronic newsletter, v.11, p.43-53, 2010.

MARTINS JR, A. The production and negotiation of difference in a world on the move: Brazilian migration to London. London, $\mathrm{PhD}$, Goldsmiths College, University of London, 2017.

. Lives in Motion: notebooks of an immigrant in London, Copenhagen: Whyte tracks, 2014.

MASSEY, D. S. Social structure, household strategies, and the cumulative causation of migration, Population Index, v.56, n.1, p.3-26, 1990.

MCCLINTOCK, A. Imperial Leather, London: Routledge, 1995.

MILLS, C. The Racial Contract, Ithaca: Cornell University Press, 1997.

NAGEL, J. Racial, Ethnic, and National Boundaries: Sexual Intersections and Symbolic Interactions, Symbolic Interaction, v.24, n.2, p.123-139, 2001.

OLIVEIRA, A. T. Fluxos Migratórios entre o Brasil e a Península Ibérica: um olhar através do Censo Demográfico de 2010, 3rd Seminar of Studies on Brazilian Migration in Europe, Intitute of Education, London/UK, 2014.

OLIVEIRA, A. C. de. O Caminho sem Volta - Classe social e etnicidade entre os brasileiros na Flórida', In: MARTES. A. C. B, and FLEISCHER, S. (eds.) Fronteiras Cruzadas: Etnicidade, Gênero e Redes, Petropolis, RJ, Brazil: Editora Paz e Terra, 2003, p.115-138.

PISCITELLI, A. Interseccionalidades, Categorias De Articulação E Experiências De Migrantes Brasileiras, Sociedade E Cultura, v.11, n.2, p.263-274, 2008.

TOGNI, P.C. A Europa é o Cacém. Mobilidades, gênero e sexualidade nos deslocamentos de jovens brasileiros para Portugal, Doctoral Thesis, ISCTE/OUL, Lisbon, 2014.

PORTER, R. Flesh in the Age of Reason, London: Allen Lane, 2003.

PORTES, A. Economic Sociology and the Sociology of Immigration: A conceptual Overview, In: PORTES, A. (ed.) The Economic Sociology of Immigration, Princeton: Russel Sage Foundation, p.1-41, 1995.

QUIJANO, A. Coloniality of Power, Ethnocentrism, and Latin America, Nepantla, v.1, n.3, p.533-80, 2000. 
Negociando diferenças culturais e de gênero essencializadas em um mundo global: Brasileiros em Londres.

PUWAR, N. Space Invaders: race, gender and bodies out of place, London: Berg, 2004.

ROGGEVEEN, S. and VAN MEETEREN, M. Beyond community: An analysis of social capital and the social networks of Brazilian migrants in Amsterdam, Current Sociology, v.61, n.7, p.1078- 1096, 2013.

SAID, E. Orientalism, New York: Pantheon Books, 1978.

SAYAD, A. The Suffering of the Immigrant, Cambridge: Polity, 2004

SCHWARCZ, L. O Espetáculo das Raças, São Paulo: Cia das Letras, 1993.

SEYFERTH, G. Imigração e Cultura no Brasil, Brasília: Editora da Universidade de Brasília, 1990.

SKEGGS, B. Formations of Class and Gender: Becoming Respectable, London: Sage, 1997.

SOARES, W. Da metáfora à substância: redes sociais, redes migratórias e migração nacional e internacional em Valadares e Ipatinga, Doctoral Thesis, Centro de Desenvolvimento e Planejamento Regional, Universidade Federal de Minas Gerais: Belo Horizonte, 2002.

SOUZA, J. A dimensão simbólica do capitalismo moderno:para uma teoria crítica da modernização, Revista Estudos Políticos, v.5, p.41-59, 2012. A gramática Social da Desigualdade Brasileira, Revista Brasileira de Ciências Sociais, São Paulo, v.19, n.54, p.79-96, 2004.

SPICKARD, P. Multiple Identities: Migrants, Ethnicity, and Membership, Bloomington: Indiana University Press, 2013.

STOLKE, V. O Enigma das Intersecções: Classe, 'Sexualidade', Sexo, Sexualidade. A Formação dos Impérios Transatlânticos do Século XVI ao XIX, Revista Estudos Feministas, v.14, n.1, p.15-42, 2006.

TILLY, C. Transplanted Networks, In: YANS-MCLAUGHLIN, V. (Ed.). Immigration Reconsidered. History, Sociology, and Politics. New York: Oxford University Press, pp. 79- 95, 1990.

TYLER, I. Revolting Subjects: Social Abjection and Resistance in Neoliberal Britain. Zed Books, 2013.

URRY, J. Mobilities. Malden: Polity Press, 2008.

VERTOVEC, S. Conceiving and researching transnationalism, Ethnic and Racial Studies, v.22, n⿳o.2, pp.447-62, 1999.

YOUNG, R. J. C. Colonial Desire: Hybridity in Theory, Culture and Race. London: Routledge, 1995. 